\title{
The Pathway to Improve Innovation Capacity for Lao Firms: The Roles of Transformational Leadership and Psychological Resources of Employees
}

\author{
Phouvong Sengphet \\ ${ }^{1}$ School of Business Administration, \\ Hunan University, Changsha, Hunan, China. \\ ${ }^{2}$ Faculty of Education, National University of Laos, Vientiane, Laos \\ Lei Hui \\ School of Business Administration, \\ Hunan University, Changsha, Hunan, China \\ Le Ba Phong* \\ ${ }^{1}$ School of Business Administration, \\ Hunan University, Changsha, Hunan, China. \\ ${ }^{2}$ Faculty of Business Management, \\ Hanoi University of Industry, Hanoi, Vietnam
}

\begin{abstract}
Innovation is the key and fundamental forces for firms to survive and grow in a competitive environment. The paper aims to examine the correlation between Transformational Leadership (TL) and employees' psychological sources and how they affect an organization's Innovation Capability (IC). Structural Equations Modeling (SEM) is utilized to elaborate the relationship among the proposal factors using survey data gathered from 315 participants of 65 medium and small-sized firms in Vientiane, Laos. The findings show that employees' psychological sources, namely optimism and self-efficacy, act as mediating roles in the effects of TL on IC. The findings revealed that TL's Idealized Influence (TII) brings employees greater optimism, while individualized consideration creates a stronger self-efficacy among employees. In addition, it highlighted the extreme importance of self-efficacy in stimulating IC compared with optimism's effect. From a practical view, the paper highlights the importance and need to apply TL style in organization management to develop employees' positive psychological capital and improve IC actively. The paper's findings also bring deeper understanding and theoretical initiatives that can be applied to clarify the correlation among TL, forms of employees' psychological capital, and IC.
\end{abstract}

Keywords: TL, positive psychological source, optimism, self-efficacy, IC

Received: 12 May 2019; Accepted: 15 July 2019; Published: 26 August 2019

\section{INTRODUCTION}

In the era of rapid technological progress and ferocious competition in the business environment, firms require to unendingly utilize their potential resources such as human capital to improve IC and viability (Coetzer, Inma, Poisat, Redmond, \& Standing, 2018; Diaz-Fernandez, Bornay-Barrachina, \& Lopez-Cabrales, 2017; P. B. Le \& Lei, 2019). IC is the key and decisive pathway for firms "to create value, to build, and to sustain competitive advantage in long term as it can be a source of competitive advantage" (Ha, Phong, \& Lei, 2019). Scholars recognized that IC of

\footnotetext{
${ }^{*}$ Correspondence concerning this article should be addressed to Le Ba Phong, School of Business Administration, Hunan University, Changsha, Hunan, China. Faculty of Business Management, Hanoi University of Industry, Hanoi, Vietnam. E-mail: lebaphong.vn@gmail.com

(c) 2019 The Author(s). Published by KKG Publications. This is an Open Access article distributed under a Creative Commons AttributionNonCommercial-NoDerivatives 4.0 International License.
} 
firms allows them to adapt effectively with the lack of certainty of both external and internal environment, and bring firms the success in the dynamic markets in long term (Hinterhuber \& Liozu, 2017; Hou, Hong, Zhu, \& Zhou, 2019; B. P. Le et al., 2018; Lei, Do, \& Le, 2019). However, it is not easy for firms to develop it properly due to lack of understanding on antecedents of innovation (Lei et al., 2019; Yang, Nguyen, \& Le, 2018). To bridge the theoretical gaps, this study focuses on investigating the impacts of transformational leaders on IC of firms based on the mediating role of two dimension of employees' psychological source namely optimism and self-efficacy. This study is expected to significantly expand the theory and bring valuable insight of innovation management by following reasons.

First, B. P. Le et al. (2018) pointed out that, leaders play a decisive role in the failure or success of an organization. Moreover, each leadership style has a certain significance and influence on organizations' specific outcomes such as innovation (De Vries, Bakker-Pieper, \& Oostenveld, 2010). Therefore, prior studies have called for exploring the appropriate leadership to improve innovative capability which helps firms being more flexible, adaptive, and entrepreneurial aimed at meeting the fast changes of today's environment (P. B. Le \& Lei, 2019; Sarros, Cooper, $\&$ Santora, 2008). Among leadership styles, TL is widely consented as one of the most dominant leadership styles facilitated innovation capabilities for firms (P. B. Le \& Lei, 2019). TL has become the hot issue that appealed the much interest of researchers and practitioners for examining leadership-innovation relationship (H. Hu, Gu, \& Chen, 2013; P. B. Le \& Lei, 2019). However, according to P. B. Le and Lei (2019), "knowledge of the direct correlation between TL and IC remains underdeveloped and insufficient. It still exist the theoretical and empirical gaps in TL-innovation relationship that need to continue exploring and studying." So the first objective of this study is to elucidate the TL-innovation relationship by looking the answer for the first research question:

RQ1. Does TL directly predict IC?

Second, employees positive Psychological Resources (PS) is considered as one of the most significant human resources of every organizations which distinguished by four dimensions namely self-efficacy, optimism, hope, and resilience (B. P. Le et al., 2018; Luthans, Youssef, Avolio, et al., 2007). Employees' PS is viewed as the strong and intrinsic resources to increase creativity and IC within an organization (Sweetman, Luthans, Avey, \& Luthans, 2011). However, the correlation between specific elements of PS (e.g., self-efficacy and optimism) and IC is still scarce and limited (Gonçalves \& Brandão, 2017; Schuckert, Kim, Paek, \& Lee, 2018). Consequently, to provider deeper knowledge of how Employees' Optimism (EO) and self-efficacy affect IC, this study efforts to show the empirical evidence for the second research question:

RQ2. Do optimism and self-efficacy directly affect IC?

Finally, although scholars suggested the positive effects of TL on PS (He, An, \& Lin, 2016) which in turn significantly related to capability of innovation (Sweetman et al., 2011; Wojtczuk-Turek \& Turek, 2015). However, according to the author's knowledge prior works have paid little attention for examining the mediating role of PS or its specific dimensions of self-efficacy and optimism in the connection between TL and IC. This has limited our understanding on the mediating processes or specific solutions according to which transformation leaders can follow to successfully increase IC for firms. As a result, to clearly possible mediating role of EO and self-efficacy between leadership-innovation relationships, the third objective of this study is throwing light on such issue by posing the last research question.

RQ3. Do optimism and self-efficacy serve as mediator between TL and IC?

To clarify three research questions above, this paper has reviewed the literature and used the data gathered from the survey questionnaires in the contexts of firms in Vientiane, capital of Laos. We expect to offer specific and useful guidance for firms in developing countries to succeed in improving their IC.

This study has structured in five parts. The introduction part shows the main purpose and significance of the research. The study then presents the research background and poses hypotheses in the second part. This study will present empirical data and research methodology in the third part. The fourth part will show the findings of the research. Finally, this study will discuss and highlight the findings, contributions, implications as well as limitations of the research in the last part. 


\section{THEORETICAL BACKGROUND}

\section{The Effects of TL on IC}

IC is one of the most important dynamics that enable firms to attain competitive advantage and success in long term in comparison with the key rivals (Çakar \& Ertürk, 2010; Lei et al., 2019; Nguyen, Phong, Hui, et al., 2019). Literature defined innovation in many different ways (Baregheh, Rowley, \& Sambrook, 2009; Çakar \& Ertürk, 2010; P. B. Le \& Lei, 2019). For example, according to Çakar and Ertürk (2010), IC refers firm's ability to mobilize and combine the organizational knowledge resource to create new product and/or process innovation. According to Francis and Bessant (2005), innovation capabilities can be seen as the changes in products or/and service offered to the market by organizations. Damanpour (2010) stressed that, IC reflects the creation or adoption of an idea or behavior that is new to the organization. This study considers IC as the "process of the introduction and implementation of new ideas, products, services, procedures, technology, organizational structures, plans and programs, with the purpose of increasing organizational performance, and achieving organizational success" (Than, Nguyen, Tran, \& Le, 2019).

Leadership widely accepted as a determinant factor for innovation. Previous works highlighted that leaders directly affect innovation by creating appropriate conditions within an organization to positively assist the process of generating and implementing activities of innovation (Ha et al., 2019; Jia, Chen, Mei, \& Wu, 2018; Podrug, Filipović, \& Kovač, 2017). They also directly involved in promoting IC by develop a positive climate for process of knowledge sharing among employees (P. B. Le \& Lei, 2019), or by generating a support climate that supports the experiments as well as the action of introducing new initiatives, activities, procedures or structures (Trung, Nghi, Soldier, Hoi, \& Kim, 2014). TL is well known as one of the super leadership styles that notably associated with organizational capabilities for innovation (P. B. Le \& Lei, 2019). Scholars describes the transformational leaders with four attributes: (1) idealized influence refers transformational leaders' ability in providing a vision and insight of mission, inculcating the pride, and obtaining esteem and trust from employees; (2) intellectual stimulation expresses transformational leaders' capability to encourage rationality and thorough problem solving, and to stimulate intelligence of followers; (3) inspirational motivation manifests transformational leaders' concerns in sharing or exchanging information with high expectations, utilizing symbols to focus efforts, and conveying key intentions or objectives in simple methods; and (4) individualized consideration reflects transformational leader' interest in meeting employees' needs, coaching, advising, treating each employee individually (Bass, 1985). In the similar vein, Podsakoff, MacKenzie, Moorman, and Fetter (1990) defined TL will six dimensions namely (1) communicating a clear vision for the future; (2) bringing an proper model of role; (3) encouraging the accelerant of aim or desired results; (4) establishing high expectations on performance; (5) implementing the individual assistance for employees; and (6) being interested in intellectual stimulation. Focusing on antecedents or determinant factors for innovation, this study will examine TL based on two dimensions namely idealized influence and individualized consideration because they are two most important aspects that significantly foster organizational climate for innovation (Sarros et al., 2008).

Current literature shows the clear evidence that supports the positive effects of TL on organizational capacity for innovation (e.g., (Jia et al., 2018; P. B. Le \& Lei, 2019; Rijal, 2016; Sarros et al., 2008; Van, Phong, Loan, et al., 2018; Zuraik \& Kelly, 2019). Specifically, previous studies indicated that transformational leaders create a strong and positive motivation for employees to over their self-interests which allow them unendingly innovate to follow the organizational vision (Bass, Avolio, Jung, \& Berson, 2003; Sarros et al., 2008). According to Gumusluoğlu and Ilsev (2009), by articulating a strong vision emphasized innovation, transformational leaders contribute to nurturing a fitting culture where employees feel challenged to discover innovative and effective initiatives for dealing with a certain situation. They considerably support processes of change and innovation through encouraging experimentation, exploration, communication and dialogue among employees (Trung et al., 2014; Zhang, Lu, Torres, \& Chen, 2018). Schuckert et al. (2018) found that under the leadership of transformational leaders, organizations have a greater motivation to innovate. Recently, P. B. Le and Lei (2019) empirical research in China context indicated that transformational leaders are directly and indirectly associated with innovation capabilities through shaping and instilling a support culture of sharing knowledge among employee that positively improve organization's capability for product and process innovation.

Although TL is broadly considered as one of the determinant factors that positively and significantly associated with innovation capabilities of firms, more evidence on effects of TL's specific dimensions on IC are necessary. So, we proposed that (Figure 1):

H1a: Idealized influence positively contributes to IC. 
H1b: Individualized consideration positively contributes to IC.

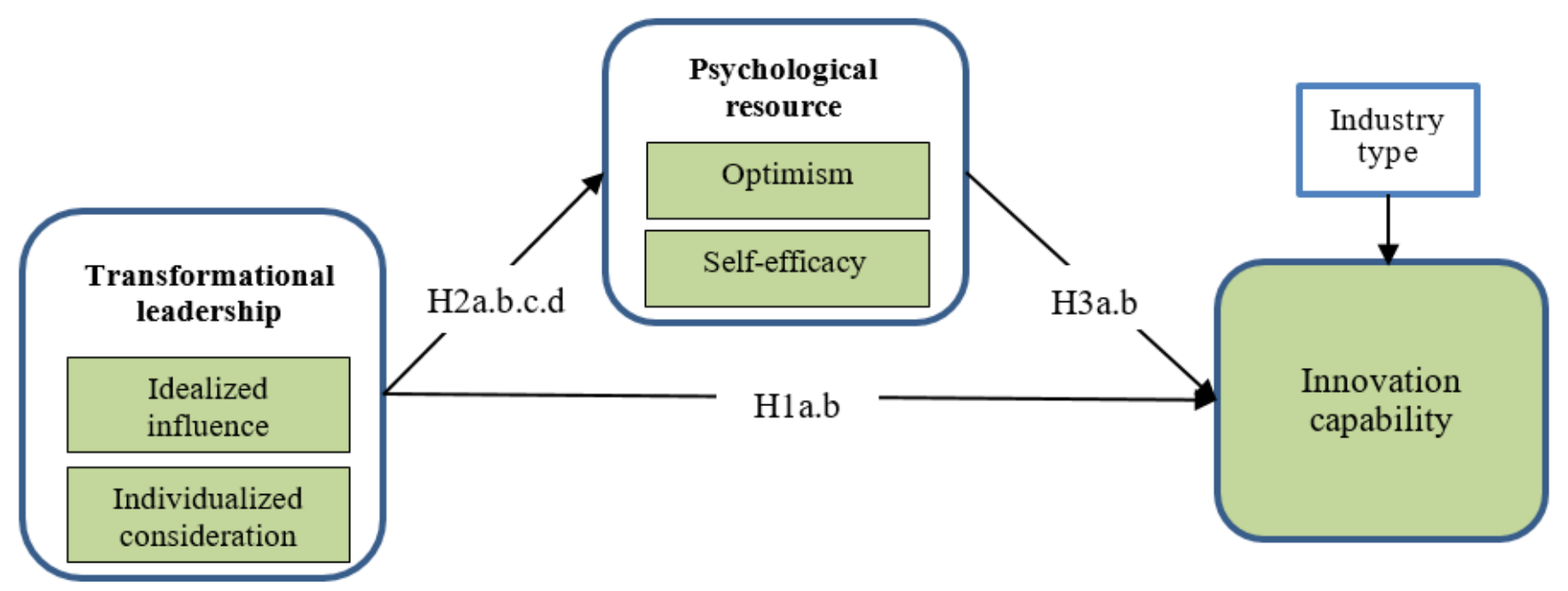

Figure 1 The Conceptual Model

\section{PS Mediates the Relationship Between TL and IC}

Individuals' positive PS is emerging as one of most interesting topics in the theory of organizational behavior and human resource in recent years due to its crucial impacts on many aspects of organization's outcomes (Gupta, Shaheen, \& Reddy, 2017; Hairudinor, Hidayati, Muspiron., Tampubolon, \& Humaidi., 2017; Luthans et al., 2007; Özsungur, 2019; Pimonratanakan, Intawee, Krajangsaeng, \& Pooripakdee, 2017; Zhang et al., 2018). PS is regarded as a composite construct of employees' positive strengths and virtues which allow employees to overcome the arising troubles and attain desired targets (Luthans, 2012; Luthans et al., 2007). Luthans et al. (2007) described PS as an individual's positive mental and emotional state represented by four elements: optimism, self-efficacy, hope, and resilience. Optimism describes the individuals' positive view of life, and well-being. It is also used to denoting the individuals' expectancy for positive and possible outcomes in the future (B. P. Le et al., 2018); self-efficacy refers to the individuals' belief in their capabilities to make use of their motivation, cognitive resources and action plan to fulfill the assigned tasks (Luthans et al., 2007); hope is used to expressing the positive thoughts and feelings that individuals have for their goals (Snyder, 2002); finally, resilience reflects a high vigor allowing individuals to keep on trying and doing their best in the situation of facing with failures, calamities, life paradoxes, and high risks (Larson \& Luthans, 2006; Ziyae, Mobaraki, \& Saeediyoun, 2015). Human resource and employees' PS are the main driving force for firms to attain organization's important mission and goals. It is important to acknowledge how leadership affects each specific aspect of employees' PS. Furthermore, prior works indicated that self-efficacy and optimism are two strategic dimensions of employees' positive psychological capital which have potential and substantial influences on knowledge sharing and IC (B. Hu \& Zhao, 2016; Jaiswal \& Dhar, 2015; B. P. Le et al., 2018). So, this study focuses on examining the impacts of TL on EO and self-efficacy.

TL is one of the most powerful leadership styles for improving human capital and key organizational outcomes. P. B. Le and Lei (2018) stated that transformational leaders "motivate their followers to fulfil duties beyond expectations by emphasizing the importance and value of goals and overcoming self-interest for the common benefit of the organization". TL theory asserted the leaders' ability in arousing employees to reach the high degrees of performance or outcomes by promoting their positive emotions, feeling, attitudes, beliefs, and values (Bass, 1985). The positive effect of transformational leaders on employees' PS is reflected quite clearly in current literature. Specifically, according Gooty, Gavin, Johnson, Frazier, and Snow (2009), by articulating a powerful vision by means of stories, metaphors, personal reflections, and images, TL not only advances the employees' capability to put down goals and have high belief in their opportunity to successfully execute those goals and tasks that closely link with the vision but also create employees' positive appraisal of the future. Under leadership by transformational leaders, employees will have a greater commitment to collective goals, and stronger confidences in the ability of achieving these goals. As a result, they have the higher degrees of efforts and greater beliefs to achieve a beautiful future. In other words, TL is significantly related to employees' PS (Eid, Mearns, Larsson, Laberg, \& Johnsen, 2012). More specifically, relating to TL-optimism 
relationship, McColl-Kennedy and Anderson (2002) argued that TL generates a high degree of psychological optimism from employee through their significant support and consideration. Furthermore, their empirical findings indicated that TL directly affects EO to increase performance. Regarding the correlation between TL and self-efficacy, Pillai and Williams (2004) reported that TL is positively and directly to Employees' Self-efficacy (ES). Liu, Siu, and Shi (2010) denoted that TL is the important determinant of both ES and satisfaction. Recently, B. P. Le et al. (2018) confirmed that TL has considerable influence on EO and self-efficacy which in turn lead to a positive climate of knowledge sharing activities in an organization.

The above discussion clearly shows the positive effects of TL on employees' PS. Indeed, by considering/caring for individuals, and inspiring, transformational leaders can bring employees a high confidence in their own abilities as well as optimism in the positive results and good prospects of the organization. However, empirical evidence on the correlation between decisive traits of TL and specific elements of employees' positive PS namely self-efficacy and optimism is still deficient and sparse (B. P. Le et al., 2018). Therefore, to clarify the TL's impacts on employees' PS, following hypotheses are posed:

\section{H2a: Idealized influence significantly affects optimism}

\section{H2b: Idealized influence significantly affects Self-efficacy}

\section{H2c: Individualized consideration significantly affects optimism}

H2d: Individualized consideration significantly affects self-efficacy.

With respect to the relationship between employees' PS and IC, current literature showed that employees' PS is the antecedent of IC (Rego, Sousa, Marques, \& e Cunha, 2012). According to Luthans and Youssef (2004), and Rego et al. (2012), self-efficacious employees have a great confidence in their competence to foster the motivation, cognition, and positive activities to effectively execute a certain duty in a specified situation. They are likely to follow the challenging tasks, and used to applying the efforts and motivational resources to fulfill their goals, as well as persevering to face with obstacles and difficulties. Such challenging goals and motivation inspire employees to propone new and valuable initiatives and ideas for improving innovation. Meanwhile, optimists tend to be more positive about-face on hard circumstances. They also have positive feelings and emotions, and persevere to overcome difficulties. They always explore for new and effective solutions to successfully resolve the hobbles and maximize the opportunities (Youssef \& Luthans, 2007). Generally, optimists have high belief in fine occurrences in their lives which bolsters their self-esteem and morale, and brings greater creativity in their activities and decisions (Lyubomirsky, Tkach, \& DiMatteo, 2006; Putri, 2015; Rego et al., 2012; Taiwan, Na-Nan, \& Ngudgratoke, 201). Sartori, Favretto, and Ceschi (2013) literature review found that human and psychological capital can play dominant role in organizational innovation, especially in open innovation. Psychological capital is also acknowledged as the crucial precursors to the favorable outcome of employees' process of integrating knowledge and knowledge sharing (B. P. Le et al., 2018). This allows organizations to have greater IC because "innovation initiatives mostly arise from the process of sharing knowledge, experience, and skill” (P. B. Le \& Lei, 2019). Abbas and Raja (2015) pointed out that the employees' PS dimensions are the main motivation to trigger innovative behaviors in the workplace. These scholars showed the evidence that PS is positively associated with innovation performance in Pakistani firms. Recently, Hsu and Chen (2017) cross-level research based on 922 participants from the organization in Taiwan showed that employees who have higher psychological capital will have more motivation for creative and innovative activities. In general, the high degree of optimism and confidence allow employees to have a good and strong mentality to be able to come up with new and creative ideas or experiments aimed at conquering the challenging goals and bringing the organization development. The above argument leads to the following hypotheses:

H3a: Optimism is positively related to IC.

H3b: Self-efficacy is positively related to IC.

Above discussion provides supports for the mediating role of employees' PS in the TL's effect on IC. Employees' PS is also identified as an important mediator of leadership-based organization's outcomes. For example, Rego et al. (2012) indicated that authentic leadership estimates in advance the creativity of employees both directly and indirectly via the mediating mechanism of positive psychological capital of employees. Gupta et al. (2017) demonstrated that employees' positive psychological capital significantly mediates the correlation between leader behaviors in the R\&D environment 
and creative performance behaviors. Gonçalves and Brandão (2017) study suggested the leader's humility is related to team creativity where team's psychological sources acts as mediator. Wang, Zheng, and Zhu (2018) findings revealed that TL influenced employee voice behavior via the mediating roles of employees' PS. Özsungur (2019) recently show the mediating role of psychological capital in the ethical leadership's influence on service innovation behavior. Based on the above discussion, we argued that the strong and positive traits of TL (such as idealized influence and individualized consideration) allow transformational leaders to bring employees greater self-efficacy and optimism in doing works which in turn motive them become more creative and innovative to fulfill their duties. Although, the mediating role of employees' PS between leadership and organization's outcomes is clear and shown by current literature, it is still lacking of how aspects of PS (optimism and self-efficacy) mediate the effects of TL's main traits on IC. So, following hypotheses are tested:

H4a: PS mediates between TII and IC.

H4b: PS mediates between TIC and IC.

\section{RESEARCH METHODOLOGY}

\section{Sample and Measures}

The paper employs a survey method for collecting data. Specifically, we used convenient sampling method to collect data from 65 small and medium firms in Vientiane, Laos during the period from July to November, 2018. Approached firms are diverse in industries, sizes and operating in distinct fields. Initially, to make easy for data collection in the context of a developing country like Laos, we contacted with the representatives of the HR departments in person or via e-mail. We then interpret the research goals and request for their help in distributing questionnaires and collecting data. To meet the purpose of the research, the participants in our study need to be the heads of department, and key employees from major departments/divisions of administration, accounting, operation, marketing, and research and development to make the certain that they have multiple and full knowledge on their organization's operation. This study distributed 610 questionnaires and received back 392 in the formal data collection, of which 315 are valid (51.6\% validity rate). We used the Armstrong and Overton (1977) method to assess potential non-response bias. We implemented the chi-square and independent sample $t$-tests to estimate the first 95 participants and the last 95 ones through the demographic factors namely age and gender. The outcomes indicated that there is no significant differentiation among the two participant groups $(p>0.05)$.

\section{Measurement}

To make sure the study's validness and reliableness, this study has used the items originated by prior studies to measure latent variables in the research model. All structures/factors are assessed by using multiple indicators and all of them were calculated through a five-point Likert-type scale, ranging from " $1=$ strongly disagree" to " $5=$ strongly agree."

TL: To measure the perception of employees about their leader's TL behaviors, we use nine items originated from research of Podsakoff et al. (1990). Where idealized influence is measured based on five items to express TL's behavior in developing, articulating, and inspiring others with leaderships' vision of the future. A sample item is, "My leader paints an interesting picture of the future for our group." Individualized consideration is measured through four items that manifest the concern of TL for employees' personal feelings and needs. A sample item is, "My leader behaves in a manner thoughtful of my personal needs." Results of Confirmatory Factor Analysis (CFA) that combines idealized influence and idividualized consideration showed an acceptable fit to a one-factor model $\left(\chi^{2}=54.27\right.$, $\mathrm{df}=26$; Root Mean Square Error of Approximation (RMSEA) = 0.06; Goodness of Fit Index (GFI) = 0.96; Comparative Fit Index $(\mathrm{CFI})=0.98$; Normed Fit Index $(\mathrm{NFI})=0.97$; Tucker-Lewis Index $(\mathrm{TLI})=0.98$; Incremental Fit Index $(\mathrm{IFI})=0.98)$.

Self-efficacy and optimism: To measure self-efficacy of employees, we used 12 items from Luthans et al. (2007) Psychological Capacity Questionnaire to measure self-efficacy (six items) and optimism (six items). Sample items are, "I feel confident presenting information to a group of colleagues" (self-efficacy); and "I always look on the bright side of things regarding my job" (optimism). A CFA combining self-efficacy and optimism met satisfactory levels $\left(\chi^{2}=146.08, \mathrm{df}=52 ; \mathrm{RMSEA}=0.08 ; \mathrm{GFI}=0.93 ; \mathrm{CFI}=0.96 ; \mathrm{NFI}=0.95 ; \mathrm{TLI}=0.95 ; \mathrm{IFI}=0.96\right)$, supporting the distinction between the two dimensions of Psy-Cap. 
Innovation capabilities: We used six scales from Lin (2007) to reflect firm's ability in offering customers new products as well as applying the new methods and process to get better performance. A samples item is: "Our firm is frequently the first to market new products and services". A CFA model also met satisfactory levels $\left(\chi^{2}=56.433\right.$, df $=8$; RMSEA $=0.10 ; \mathrm{GFI}=0.94 ; \mathrm{CFI}=0.97 ; \mathrm{NFI}=0.97 ; \mathrm{TLI}=0.96 ; \mathrm{IFI}=0.97)$, supporting the distinction between the two aspects of innovation.

Control variables: This study use industry type to control for the differences in innovation capabilities among firms. It is consistent with research of P. B. Le and Lei (2019).

\section{Data Analysis Methods}

To avoid the influences of common method bias, the paper has implemented the Harman's single-factor test to examine for common method bias. The findings pointed out that the overall variance is less than the $50 \%$ threshold for substantive common method variance. Such result has shown that common method bias is not a concern. The paper also applied the SEM to check the proposal hypotheses in initial proposal model. Beside, this paper has also implemented a bootstrapping procedure for the significance tests. Statistical Package for the Social Sciences (SPSS 21) and Analysis of Moment Structures (AMOS 21) are employed for assessing the data gathered from the 315 respondents in 65 small and medium firms.

\section{RESULTS}

\section{Measurement Model}

Before testing the hypotheses, a series of tests are performed to assess the validity and reliability of the constructs. Specifically, to assess the reliability of the latent variables, basing on suggestion of Nunnally (1994), this study used the Cronbach's alpha coefficients of each one that require greater than the level of 0.7. As shown in Table 1, the statistic results indicated that Cronbach's alpha coefficients lie from 0.88 to $0.96(>0.7)$ which showed the evidence for the reliability of scales. To check for the convergent validity of each latent variable, the paper has performed the CFA. The Table 1 reported that the standardize loadings of items used to measure the same structure are statistically significant ( $t$-values ranging from 14.3 to 26.1 are higher than 1.96). The results have provided the evidence for the convergent validity of constructs (Bagozzi \& Yi, 1988).

Finally, for evaluating the discriminant validity of latent constructs in the proposal model, the paper used the squared correlations among the latent factors to control whether they are smaller than each latent variable's square root of AVE or not. Table 2 points out that the squared correlations among the latent factors are lower than square root of AVE of each one (diagonal elements in bold). Thus, according to Fornell and Larcker (1981), the results have provided significant support for the scales' discriminant validity.

Table 1 FACTOR LOADING AND RELIABILITIES OF MEASUREMENT MODEL

\begin{tabular}{|c|c|c|c|c|c|c|}
\hline Construct & Item & Standardize loading & $t$-value & $\mathrm{CR}$ & AVE & $\mathrm{C} \alpha$ \\
\hline \multirow[t]{6}{*}{ TII } & 5 & - & - & 0.93 & 0.74 & 0.93 \\
\hline & TII1 & $0.83 * * *$ & 20.8 & & & \\
\hline & TII2 & $0.86 * * *$ & 22.5 & & & \\
\hline & TII3 & $0.90 * * *$ & 23.4 & & & \\
\hline & TII4 & $0.84 * * *$ & 21.3 & & & \\
\hline & TII5 & $0.86^{* * *}$ & 22.4 & & & \\
\hline
\end{tabular}


TABLE 1 CONTINUE

\begin{tabular}{|c|c|c|c|c|c|c|}
\hline Construct & Item & Standardize loading & $t$-value & $\mathrm{CR}$ & AVE & $\mathrm{C} \alpha$ \\
\hline \multirow[t]{5}{*}{ TIC } & 4 & - & - & 0.88 & 0.66 & 0.88 \\
\hline & TIC1 & $0.86^{* * *}$ & 17.8 & & & \\
\hline & TIC2 & $0.76 * * *$ & 15.8 & & & \\
\hline & TIC3 & $0.79 * * *$ & 16.5 & & & \\
\hline & TIC4 & $0.83 * * *$ & 17.8 & & & \\
\hline \multirow[t]{7}{*}{$\mathrm{EO}$} & 6 & - & - & 0.93 & 0.68 & 0.93 \\
\hline & EO1 & $0.85^{* * *}$ & 19.7 & & & \\
\hline & $\mathrm{EO} 2$ & $0.79 * * *$ & 17.2 & & & \\
\hline & EO3 & $0.82 * * *$ & 18.4 & & & \\
\hline & EO4 & $0.76^{* * *}$ & 16.4 & & & \\
\hline & EO5 & $0.86 * * *$ & 19.8 & & & \\
\hline & EO6 & $0.85 * * *$ & 19.7 & & & \\
\hline \multirow[t]{7}{*}{ ES } & 6 & - & - & 0.91 & 0.63 & 0.91 \\
\hline & ES1 & $0.79 * * *$ & 16.3 & & & \\
\hline & $\mathrm{ES} 2$ & $0.82 * * *$ & 16.9 & & & \\
\hline & ES3 & $0.72 * * *$ & 14.3 & & & \\
\hline & ES4 & $0.78 * * *$ & 16.0 & & & \\
\hline & ES5 & $0.82 * * *$ & 17.1 & & & \\
\hline & ES6 & $0.80 * * *$ & 16.8 & & & \\
\hline \multirow[t]{7}{*}{ IC } & 6 & - & - & 0.96 & 0.80 & 0.96 \\
\hline & IC1 & $0.89 * * *$ & 26.1 & & & \\
\hline & $\mathrm{IC} 2$ & $0.85^{* * *} *$ & 21.9 & & & \\
\hline & IC3 & $0.90 * * *$ & 15.1 & & & \\
\hline & IC4 & $0.89 * * *$ & 26.1 & & & \\
\hline & IC5 & $0.91 * * *$ & 20.1 & & & \\
\hline & IC6 & $0.90 * * *$ & 25.3 & & & \\
\hline
\end{tabular}

Notes: $\mathrm{C} \alpha \geq 0.7 ; \mathrm{CR} \geq 0.7 ; \mathrm{AVE} \geq 0.5 ; * * * p<0.001$

Descriptive statistics: The Standard Deviations (SD), Means, and correlation coefficients among the factors in the proposal conceptual model are shown in the Table 2.

Table 2 DESCRIPTIVE STATISTICS AND CONSTRUCT CORRELATIONS

\begin{tabular}{|c|c|c|c|c|c|c|c|}
\hline Constructs & Mean & S.D & TII & TIC & EO & ES & IC \\
\hline TII & 3.39 & 0.61 & 0.86 & & & & \\
\hline TIC & 3.45 & 0.62 & $0.59 * * *$ & 0.81 & & & \\
\hline $\mathrm{EO}$ & 3.71 & 0.60 & $0.68 * * *$ & $0.63 * * *$ & 0.82 & & \\
\hline ES & 3.62 & 0.58 & $0.67 * * *$ & $0.76 * * *$ & $0.69 * * *$ & 0.79 & \\
\hline IC & 3.95 & 0.64 & $0.66 * * *$ & $0.69 * * *$ & $0.72 * * *$ & $0.77 * * *$ & 0.89 \\
\hline
\end{tabular}

\section{FINDINGS}

The paper applied Structural equation model with procedures of maximum likelihood estimation to examine the proposal hypotheses. The findings in Table 3 suggest the fit indices of the proposal model. Specifically, the fit indices 
are satisfactory $\left(\chi^{2}=629.36\right.$; $\mathrm{df}=337$; RMEA $=0.053$; $\mathrm{GFI}=0.877 ; \mathrm{CFI}=0.963$; $\left.\mathrm{TLI}=0.958\right)$. The results have pointed out that the correlation among latent factors fit the data.

Table 3 MODEL FIT INDICES OF THE STRUCTURAL MODEL

Fit index

Absolute fit measures

CMIN/df

GFI

RMSEA

Incremental fit measures

NFI

AGFI

CFI
Scores

1.868

0.877

0.053

0.923

0.851

0.963
Recommended value

$\leq 2^{\mathrm{a}} ; \leq 5^{\mathrm{b}}$

$\geq 0.90^{\mathrm{a}} ; \geq 0.80^{\mathrm{b}}$

$\leq 0.8^{\mathrm{a}} ; \leq 0.10^{\mathrm{b}}$

$\geq 0.90^{\mathrm{a}}$

$\geq 0.90^{\mathrm{a}} ; \geq 0.80^{\mathrm{b}}$

$\geq 0.90^{\mathrm{a}}$;

Notes: a Acceptability: acceptable; b Acceptability: marginal

The main findings of this study are shown in Table 4 and Figure 2:

\section{Direct Effect Analysis}

The results (Table 4, and Figure 2) show that direct effects of independent factors on dependent factors are found to be significant supported hypotheses H1a.1b, H 2a.2b.c.d, and H33a.3b.

Specifically, TII and TIC on IC are statistically significant, favoring for hypothesis H1a.1b. The results showed that the impacts of TIC on IC $(\beta=0.176 ; p<0.05)$ is more significant than idealized influence's influences on IC $(\beta=$ $0.113 ; p<0.1)$.

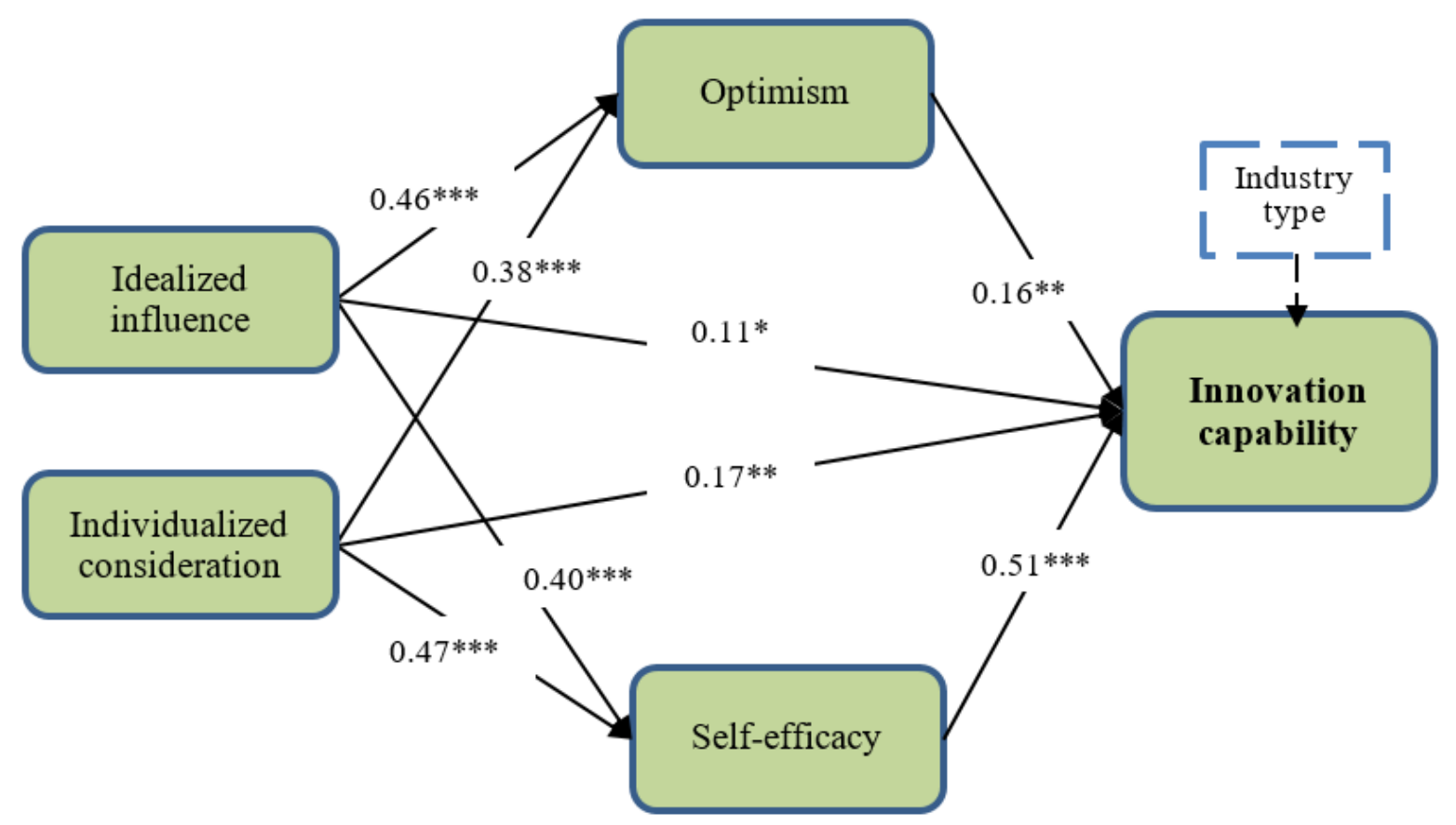

Note : $* * * p<0.001 ; * * p<0.05 ; * p<0.1 ;----$ Non-significant paths

Figure 2 Path Coefficients of the Structural Model

$\mathrm{H} 2 \mathrm{a}$ and $\mathrm{H} 2 \mathrm{~b}$ relating to correlation between TII on optimism and self-efficacy are statistically significant and quite large, so hypothesis H2a.2b is supported. The findings revealed that effect of TII on optimism $(\beta=0.468 ; p<0.001)$ is more significant than its impact on self-efficacy $(\beta=0.404 ; p<0.001)$. 


\begin{tabular}{lcccc} 
Hypotheses & Proposal effect & Estimate & $t$-value & Results \\
\hline H1a. Idealized influence $\rightarrow$ IC & & & & \\
H1b. Individualized consideration $\rightarrow$ IC & + & $0.113^{*}$ & 1.930 & Supported \\
H2a. Idealized influence $\rightarrow$ Optimism & + & $0.176^{* *}$ & 2.799 & Supported \\
H2b. Idealized influence $\rightarrow$ Self-efficacy & + & $0.468^{* * *}$ & 7.959 & Supported \\
H2c. Individualized consideration $\rightarrow$ Optimism & + & $0.404^{* * *}$ & 7.033 & Supported \\
H2d. Individualized consideration $\rightarrow$ Self-efficacy & + & $0.380^{* * *}$ & 6.377 & Supported \\
H3a. Optimism $\rightarrow$ IC & + & $0.476^{* * *}$ & 7.836 & Supported \\
H3b. Self-efficacy $\rightarrow$ IC & + & $0.163^{* *}$ & 2.815 & Supported \\
Industry type $\rightarrow$ IC & + & $0.510^{* * *}$ & 7.546 & Supported \\
\hline
\end{tabular}

Note: $* * * p<0.001 ; * * p<0.05 ; * p<0.1$.

Hypothesis $\mathrm{H} 2 \mathrm{c} .2 \mathrm{~d}$ referring the positive effects of TIC on optimism and self-efficacy are also supported. However, in contrast with $\mathrm{H} 2 \mathrm{a} .2 \mathrm{~b}$, the findings showed that the influence of individualized consideration on self-efficacy $(\beta=$ $0.476 ; p<0.001)$ is larger than its impact on optimism $(\beta=0.380 ; p<0.001)$.

The results in Table 4 also confirmed the positive effect of optimism and self-efficacy on IC (Hypotheses of $\mathrm{H} 3 \mathrm{a}$ and $\mathrm{H} 3 b)$. Specifically, it indicated that ES has a greater influence on IC $(\beta=0.510 ; p<0.001)$ in comparison with effects of employees' psychological optimism on IC $(\beta=0.163 ; p<0.05)$.

The results of testing the hypotheses are acquired after checking the roles of controlling factors namely industry type. As shown Table 4, the findings did not support the controlling role of industry type due to its influence on IC is not statistical significant. In other words, the findings underlined that the variance in industry types among firms does not result in the distinction of their capability for innovation.

\section{Analysis of Indirect Effect and Total Effect}

The paper does not just give evidence about the direct influence of TL on IC. It also demonstrates how mediating process affects the relationship between TL and IC. According to the recommendation of Preacher and Hayes (2008), to show the evidence for the positive PS's mediating roles between two main components of TL's behavior namely idealize influence and individualized consideration and IC, the paper has applied procedure of bootstrap confidence intervals with 5,000 iterations to examine and assert the indirect effects' immensity and statistical significance. The results are shown in the Table 5.

Table 5 TEST FOR INDIRECT EFFECTS

Path Direct effects Indirect effects Total effects

Bias-corrected confidence intervals Lower confidence level Upper confidence level

$\begin{array}{llllll}\mathrm{TII} \rightarrow \mathrm{PS} \rightarrow \mathrm{IC} & 0.113^{*} & 0.282 * * * & 0.395 * * * & 0.200 & 0.387 \\ \mathrm{TIC} \rightarrow \mathrm{PS} \rightarrow \mathrm{IC} & 0.176^{* *} & 0.305^{* * *} & 0.481 * * * & 0.217 & 0.413\end{array}$

Note: $* * * p<0.001 ; * * p<0.05 ; * p<0.1$.

Table 5 showed indirect effects of idealized influence and individualize consideration on IC have $\beta=0.282$ (which lies in the confidence intervals: $0.200-0.387$ ) and $\beta=0.421$ (the confidence intervals is $0.217-0.413 ; p<0.001$ ). Consequently, hypothesis $\mathrm{H} 4 \mathrm{a} .4 \mathrm{~b}$ is significant. In other words, the result of testing in Table 5 has confirmed that employees' PS significantly mediates the effects of TL's specific components on organization capability for innovation. The findings reveal that TL's individualize consideration plays an important role in improving IC for firm on both direct and indirect effects through the mediating roles of optimism and self-efficacy. 


\section{DISCUSSION AND CONCLUSION}

The organizational capability for innovation is increasingly important in creating sustainable competitive advantages for firms. Scholars emphasized the necessity of fostering IC in enhancing organizational performance (Garcia-Morales, Matias-Reche, \& Hurtado-Torres, 2008; Hui, Phouvong, Phong, et al., 2018; Than et al., 2019). However, many firms are still facing challenges and do not find out the suitable pathways to improve it correctly and effectively (B. P. Le et al., 2018; Nguyen et al., 2019). This attracted and created great awareness and motivation among scholars to explore for what allow organization to change and innovate successfully (B. P. Le et al., 2018; P. B. Le \& Lei, 2019; Van et al., 2018). The examination of the hypotheses proposed in current study have significantly improved and brought deeper insight on determinants or antecedents of IC. The paper has provided new and useful initiatives on both theory and practice in the fields of leadership, management psychology, and innovation management by following main points.

First, the paper contributes to bridge the theoretical cavity on TL-innovation relationship by proposing an integrated model discussing the influences of TL on aspects of employees' PS namely optimism and self-efficacy, which in turn affect IC. The empirical findings have demonstrated the correlation among latent variables in the proposal model and indicated that as one of the most effective leadership styles, transformational leaders have a positive and significant position in enhancing the positive PS of employees and IC of organization. More importantly, the findings revealed that the individualized consideration of TL has a greater impact on IC in comparison with the effect of idealized influence. The findings imply that to improve IC especially in case of small and medium firms, managers/directors should pay much attention to employees' personal thoughts and feelings. The main reason can explain for the important role of the individualized consideration is that it might serve "as a carrot or motivational tool" for arousing the greater affection and efforts of employees to be creative and innovative (P. B. Le \& Lei, 2019; Luthans et al., 2007; Schuckert et al., 2018).

Second, an important contribution of this study is that analysis more deeply the relationship between two key components of TL and two main aspects of employees' positive psychological capital namely optimism and self-efficacy. Consequently, the findings on relationships between these constructs have provided more specific and useful guides for firms to pursuit improving each psychological trait of employees. Specifically, the findings disclosure that idealized influence brings employees greater optimistic, meanwhile individualized consideration can shape a stronger confidence among employees. The findings have contributed to deeper understandings on specific ways leading to specific dimension of employees' PS. These findings are very interesting and valuable because the difference in employees' psychological state can produce different results in the process of human activities in an organization.

Third, positive psychological asset of employees is considers one of the most important intrinsic motivation enable them to be more creative and innovative at the work place (Luthans et al., 2007). However, the mechanism of how PsyCap mediates the effects of leadership on innovation is still limited (Gonçalves \& Brandão, 2017; Luthans, 2012). To bridge the research gaps, this paper has proposed a research model to link TL and innovation via mediating role of employees' PS. The empirical findings have firstly confirmed the mediating effects of optimism and self-efficacy between TL and IC, and indicated that TL is an important predictor of employees' PS which in turn bring greater motivation for employee to innovate. Especially, the paper reveals that self-efficacy is extremely important psychological trait for improving innovation in comparison with optimism. It might be that employees with higher self-efficacy are likely more inventive, resourceful, and perseverance to overcome obstacles for implementing innovation and improving performance (Abbas \& Raja, 2015; Tierney \& Farmer, 2002). The paper, therefore, serves as a valuable reference for managers/directors to realize effective pathways or processes leading to innovation. In generally, one of the most important contributions of the paper is to outline the specific and optimal road for both small and medium enterprises in Laos and in developing countries to perform innovation. The main reason is that small and medium enterprises in developing countries often lack of capitals and resources (Geldes, Felzensztein, \& Palacios-Fenech, 2017; Nguyen et al., 2019), so improving innovation capacity for firms by huge investments in technological innovation is not feasible. As a result, improving employees' positive psychological capital for increasing IC might be least expensive solution and wisest choice for most of small and medium firms.

\section{Limitations}

Beside significant contributions, the paper still has some certain limitations. First, the paper use cross-sectional design, thus it might expose the cases that causal correlations might alter in the long-run. Therefore longitudinal studies are necessary to surpass this restriction and confirm the findings of this study. Second, the paper has not investigated 
the impacts of various moderating or/and mediating factors like firm age and firm size in the connection among the latent factors. Future works should inspect and examine deeper the correlation among them in case of having these mediators and moderators to bring more valuable understanding for scholars and practitioners. Finally, the paper is only performed in the circumstances of medium and small firms, so the future work should examine the relationship among the latent factors in the broader circumstances to provide more meaning for firms.

\section{Conclusion}

Overall, the paper has shown the empirical evidence to spotlight that TL style and employees' positive PS significantly contribute to foster organizational capability for innovation. The paper has significantly advanced the innovation management theory by offering an integrative model and specific pathways leading to improving IC. The paper implies that by focusing attention on practicing TL style; attempting to meeting employees' thoughts and feelings; and focusing on nurturing and developing ES, firms can successfully foster their capabilities for innovation.

\section{ACKNOWLEDGMENT}

The authors appreciate aids from the National Natural Science Foundation of China under Grant No.71272208, 71521061 and 71790593, and the Ministry of Education foundation for humanities and social sciences (No.17YJA630041). We also appreciate the aids from the National Foundation for Science and Technology Development (NAFOSTED) of Vietnam in process of implementing this study.

\section{REFERENCES}

Abbas, M., \& Raja, U. (2015). Impact of psychological capital on innovative performance and job stress. Canadian Journal of Administrative Sciences/Revue Canadienne des Sciences de l'Administration, 32(2), 128-138. doi: https://doi.org/10.1002/cjas.1314

Armstrong, J. S., \& Overton, T. S. (1977). Estimating nonresponse bias in mail surveys. Journal of Marketing Research, 14(3), 396-402. doi:https://doi.org/10.2307/3150783

Bagozzi, R. P., \& Yi, Y. (1988). On the evaluation of structural equation models. Journal of the Academy of Marketing Science, 16(1), 74-94. doi:https://doi.org/10.1007/BF02723327

Baregheh, A., Rowley, J., \& Sambrook, S. (2009). Towards a multidisciplinary definition of innovation. Management Decision, 47(8), 1323-1339. doi:https://doi.org/10.1108/00251740910984578

Bass, B. M. (1985). Leadership and performance beyond expectations. New York, NY: Collier Macmillan.

Bass, B. M., Avolio, B. J., Jung, D. I., \& Berson, Y. (2003). Predicting unit performance by assessing transformational and transactional leadership. Journal of Applied Psychology, 88(2), 207-218. doi:https://doi.org/10.1037/ 0021-9010.88.2.207

Çakar, N. D., \& Ertürk, A. (2010). Comparing innovation capability of small and medium-sized enterprises: Examining the effects of organizational culture and empowerment. Journal of Small Business Management, 48(3), 325-359. doi:https://doi.org/10.1111/j.1540-627X.2010.00297.x

Coetzer, A., Inma, C., Poisat, P., Redmond, J., \& Standing, C. (2018). Job embeddedness and employee enactment of innovation-related work behaviours. International Journal of Manpower, 39(2), 222-239. doi:https://doi.org/ 10.1108/IJM-04-2016-0095

Damanpour, F. (2010). An integration of research findings of effects of firm size and market competition on product and process innovations. British Journal of Management, 21(4), 996-1010.

De Vries, R. E., Bakker-Pieper, A., \& Oostenveld, W. (2010). Leadership=communication? The relations of leaders' communication styles with leadership styles, knowledge sharing and leadership outcomes. Journal of Business and Psychology, 25(3), 367-380. doi:https://doi.org/10.1007/s10869-009-9140-2

Diaz-Fernandez, M., Bornay-Barrachina, M., \& Lopez-Cabrales, A. (2017). Hrm practices and innovation performance: A panel-data approach. International Journal of Manpower, 38(3), 354-372. doi:https://doi.org/10.1108/ IJM-02-2015-0028

Eid, J., Mearns, K., Larsson, G., Laberg, J. C., \& Johnsen, B. H. (2012). Leadership, psychological capital and safety research: Conceptual issues and future research questions. Safety Science, 50(1), 55-61. doi:https://doi.org/ 
Fornell, C., \& Larcker, D. F. (1981). Evaluating structural equation models with unobservable variables and measurement error. Journal of Marketing Research, 18(1), 39-50. doi:https://doi.org/10.1177/002224378101800104

Francis, D., \& Bessant, J. (2005). Targeting innovation and implications for capability development. Technovation, 25(3), 171-183. doi:https://doi.org/10.1016/j.technovation.2004.03.004

Garcia-Morales, V. J., Matias-Reche, F., \& Hurtado-Torres, N. (2008). Influence of transformational leadership on organizational innovation and performance depending on the level of organizational learning in the pharmaceutical sector. Journal of Organizational Change Management, 21(2), 188-212. doi:https://doi.org/10.1108/ 09534810810856435

Geldes, C., Felzensztein, C., \& Palacios-Fenech, J. (2017). Technological and non-technological innovations, performance and propensity to innovate across industries: The case of an emerging economy. Industrial Marketing Management, 61, 55-66. doi:https://doi.org/10.1016/j.indmarman.2016.10.010

Gonçalves, L., \& Brandão, F. (2017). The relation between leader's humility and team creativity: The mediating effect of psychological safety and psychological capital. International Journal of Organizational Analysis, 25(4), 687-702. doi:https://doi.org/10.1108/IJOA-06-2016-1036

Gooty, J., Gavin, M., Johnson, P. D., Frazier, M. L., \& Snow, D. B. (2009). In the eyes of the beholder: Transformational leadership, positive psychological capital, and performance. Journal of Leadership \& Organizational Studies, 15(4), 353-367. doi:https://doi.org/10.1177/1548051809332021

Gumusluoğlu, L., \& Ilsev, A. (2009). Transformational leadership and organizational innovation: The roles of internal and external support for innovation. Journal of Product Innovation Management, 26(3), $264-277$. doi:https://doi.org/10.1111/j.1540-5885.2009.00657.x

Gupta, M., Shaheen, M., \& Reddy, P. K. (2017). Impact of psychological capital on organizational citizenship behavior: mediation by work engagement. Journal of Management Development, 36(7), 973-983. doi:https://doi.org/ 10.1108/JMD-06-2016-0084

Ha, A. T. L., Phong, L. B., \& Lei, H. (2019). Leadership and organizational learning: The determinants of innovation speed and innovation quality in Vietnamese firms. Journal of Management and Strategy, 10(1), 29-37. doi:https://doi.org/10.5430/jms.v10n1p29

Hairudinor, Hidayati, N., Muspiron., Tampubolon, E., \& Humaidi. (2017). The influence of transformational leadership and compensation on psychological well-being (study at Private Hospital Nurses in South Kalimantan Province). International Journal of Business and Economic Affairs, 2(5), 317-326. doi:https://doi.org/10.24088/ ijbea-2017-25006

He, Q.-c., An, Q., \& Lin, P.-x. (2016). Transformational leadership, psychological capital and frontline sales staffs' service quality: Psychological capital as a mediator. International Journal of u-and e-Service, Science and Technology, 9(7), 309-316. doi:https://doi.org/10.14257/ijunesst.2016.9.7.31

Hinterhuber, A., \& Liozu, S. M. (2017). Is innovation in pricing your next source of competitive advantage? Innovation in Pricing, 57(3), 11-27. doi:https://doi.org/10.1016/j.bushor.2014.01.002

Hou, B., Hong, J., Zhu, K., \& Zhou, Y. (2019). Paternalistic leadership and innovation: The moderating effect of environmental dynamism. European Journal of Innovation Management, 22(3), 562-582. doi:https://doi.org/ 10.1108/EJIM-07-2018-0141

Hsu, M. L., \& Chen, F. H. (2017). The cross-level mediating effect of psychological capital on the organizational innovation climate-employee innovative behavior relationship. The Journal of Creative Behavior, 51(2), 128-139. doi:https://doi.org/10.1002/jocb.90

Hu, B., \& Zhao, Y. (2016). Creative self-efficacy mediates the relationship between knowledge sharing and employee innovation. Social Behavior and Personality: An International Journal, 44(5), 815-826. doi:https://doi.org/ 10.2224/sbp.2016.44.5.815

Hu, H., Gu, Q., \& Chen, J. (2013). How and when does transformational leadership affect organizational creativity and innovation? critical review and future directions. Nankai Business Review International, 4(2), 147-166. doi:https://doi.org/10.1108/20408741311323344

Hui, L., Phouvong, S., Phong, L. B., et al. (2018). Transformational leadership facilitates innovation capability: The mediating roles of interpersonal trust. International Journal of Business Administration, 9(3), 1-9. doi:https:// doi.org/10.5430/ijba.v9n3p1 
Jaiswal, N. K., \& Dhar, R. L. (2015). Transformational leadership, innovation climate, creative self-efficacy and employee creativity: A multilevel study. International Journal of Hospitality Management, 51, 30-41. doi: https://doi.org/10.1016/j.ijhm.2015.07.002

Jia, X., Chen, J., Mei, L., \& Wu, Q. (2018). How leadership matters in organizational innovation: A perspective of openness. Management Decision, 56(1), 6-25. doi:https://doi.org/10.1108/MD-04-2017-0415

Larson, M., \& Luthans, F. (2006). Potential added value of psychological capital in predicting work attitudes. Journal of Leadership \& Organizational Studies, 13(2), 75-92. doi:https://doi.org/10.1177/10717919070130020601

Le, B. P., Lei, H., Phouvong, S., Than, T. S., Nguyen, T. M. A., \& Gong, J. (2018). Self-efficacy and optimism mediate the relationship between transformational leadership and knowledge sharing. Social Behavior and Personality: An International Journal, 46(11), 1833-1846. doi:https://doi.org/10.2224/sbp.7242

Le, P. B., \& Lei, H. (2018). The mediating role of trust in stimulating the relationship between transformational leadership and knowledge sharing processes. Journal of Knowledge Management, 22(3), 521-537. doi:https:// doi.org/10.1108/JKM-10-2016-0463

Le, P. B., \& Lei, H. (2019). Determinants of innovation capability: The roles of transformational leadership, knowledge sharing and perceived organizational support. Journal of Knowledge Management, 23(3), 527-547. doi:https://doi.org/10.1108/JKM-09-2018-0568

Lei, H., Do, N. K., \& Le, P. B. (2019). Arousing a positive climate for knowledge sharing through moral lens: the mediating roles of knowledge-centered and collaborative culture (just accepted). Journal of Knowledge Management.

Lin, H.-F. (2007). Knowledge sharing and firm innovation capability: An empirical study. International Journal of Manpower, 28(3/4), 315-332. doi:https://doi.org/10.1108/01437720710755272

Liu, J., Siu, O.-L., \& Shi, K. (2010). Transformational leadership and employee well-being: The mediating role of trust in the leader and self-efficacy. Applied Psychology, 59(3), 454-479.

Luthans, F. (2012). Psychological capital: Implications for HRD, retrospective analysis, and future directions. Human Resource Development Quarterly, 23(1), 1-8. doi:https://doi.org/10.1002/hrdq.21119

Luthans, F., \& Youssef, C. M. (2004). Human, social, and now positive psychological capital management: Investing in people for competitive advantage. Organizational Dynamics, 33(2), 143-160. doi:https://doi.org/10.1016/ j.orgdyn.2004.01.003

Luthans, F., Youssef, C. M., Avolio, B. J., et al. (2007). Psychological capital: Developing the human competitive edge. Oxford, UK: Oxford University Press.

Lyubomirsky, S., Tkach, C., \& DiMatteo, M. R. (2006). What are the differences between happiness and self-esteem. Social Indicators Research, 78(3), 363-404. doi:https://doi.org/10.1007/s11205-005-0213-y

McColl-Kennedy, J. R., \& Anderson, R. D. (2002). Impact of leadership style and emotions on subordinate performance. The Leadership Quarterly, 13(5), 545-559. doi:https://doi.org/10.1016/S1048-9843(02)00143-1

Nguyen, D. K., Phong, L. B., Hui, L., et al. (2019). Creating competitive advantage for vietnamese manufacturing and service firms: The role of collaborative culture and innovation capability. International Journal of Business Administration, 10(2), 32-42. doi:https://doi.org/10.5430/ijba.v10n2p32

Nunnally, . B. I., J. C. (1994). Elements of statistical description and estimation. New York, NY: McGraw-Hill.

Özsungur, F. (2019). The impact of ethical leadership on service innovation behavior: The mediating role of psychological capital. Asia Pacific Journal of Innovation and Entrepreneurship, 13(1), 73-88. doi:https:// doi.org/10.1108/APJIE-12-2018-0073

Pillai, R., \& Williams, E. A. (2004). Transformational leadership, self-efficacy, group cohesiveness, commitment, and performance. Journal of Organizational Change Management, 17(2), 144-159. doi:https://doi.org/10.1108/ 09534810410530584

Pimonratanakan, S., Intawee, T., Krajangsaeng, K., \& Pooripakdee, S. (2017). Transformational leadership climate through learning organization toward the organizational development. Journal of Administrative and Business Studies, 3(6), 284-291. doi:https://doi.org/10.20474/jabs-3.6.3

Podrug, N., Filipović, D., \& Kovač, M. (2017). Knowledge sharing and firm innovation capability in Croatian ICT companies. International Journal of Manpower, 38(4), 632-644. doi:https://doi.org/10.1108/IJM-04-2016-0077

Podsakoff, P. M., MacKenzie, S. B., Moorman, R. H., \& Fetter, R. (1990). Transformational leader behaviors and their effects on followers' trust in leader, satisfaction, and organizational citizenship behaviors. The Leadership 
Quarterly, 1(2), 107-142. doi:https://doi.org/10.1016/1048-9843(90)90009-7

Preacher, K. J., \& Hayes, A. F. (2008). Asymptotic and resampling strategies for assessing and comparing indirect effects in multiple mediator models. Behavior Research Methods, 40(3), 879-891. doi:https://doi.org/10.3758/ BRM.40.3.879

Putri, Y. R. (2015). Transformational leadership and its impact to lecturers intellectual capital factors in Telkom economics and business school Telkom University. International Journal of Business and Administrative Studies, l(1), 35-41. doi:https://doi.org/10.20469/ijbas.10006

Rego, A., Sousa, F., Marques, C., \& e Cunha, M. P. (2012). Authentic leadership promoting employees' psychological capital and creativity. Journal of Business Research, 65(3), 429-437.

Rijal, S. (2016). The influence of transformational leadership and organizational culture on learning organization: A comparative analysis of the IT sector, Thailand. Journal of Administrative and Business Studies, 2(3), 121-129. doi:https://doi.org/10.20474/jabs-2.3.3

Sarros, J. C., Cooper, B. K., \& Santora, J. C. (2008). Building a climate for innovation through transformational leadership and organizational culture. Journal of Leadership \& Organizational Studies, 15(2), 145-158. doi: https://doi.org/10.1177/1548051808324100

Sartori, R., Favretto, G., \& Ceschi, A. (2013). The relationships between innovation and human and psychological capital in organizations: a review. The Innovation Journal, 18(3), 1-18.

Schuckert, M., Kim, T. T., Paek, S., \& Lee, G. (2018). Motivate to innovate: How authentic and transformational leaders influence employees' psychological capital and service innovation behavior. International Journal of Contemporary Hospitality Management, 30(2), 776-796.

Snyder, C. R. (2002). Hope theory: Rainbows in the mind. Psychological Inquiry, 13(4), 249-275. doi:https://doi.org/ 10.1207/S15327965PLI1304_01

Sweetman, D., Luthans, F., Avey, J. B., \& Luthans, B. C. (2011). Relationship between positive psychological capital and creative performance. Canadian Journal of Administrative Sciences/Revue Canadienne des Sciences de l'Administration, 28(1), 4-13. doi:https://doi.org/10.1002/cjas.175

Taiwan, A., Na-Nan, K., \& Ngudgratoke, S. (201). Relationship among personality, transformational leadership, percerived organizational support, expatriate adjustment, and expatriate performance. International Journal of Business and Administrative Studies, 3(4), 129-141. doi:https://doi.org/10.20469/ijbas.3.10001-4

Than, S. T., Nguyen, C. H., Tran, T. Q., \& Le, P. B. (2019). Building competitive advantage for vietnamese firms: The roles of knowledge sharing and innovation. International Journal of Business Administration, 10(4), 1-12. doi:https://doi.org/10.5430/ijba.v10n4p1

Tierney, P., \& Farmer, S. M. (2002). Creative self-efficacy: Its potential antecedents and relationship to creative performance. Academy of Management Journal, 45(6), 1137-1148. doi:https://doi.org/10.5465/3069429

Trung, N. N., Nghi, P. T., Soldier, L. L., Hoi, T. V., \& Kim, W. J. (2014). Leadership, resource and organisational innovation: Findings from state and non-state enterprises. International Journal of Innovation Management, 18(05), 1-30. doi:https://doi.org/10.1142/S1363919614500340

Van, N. T., Phong, L. B., Loan, L. T., et al. (2018). Antecedents of innovation capability: The role of transformational leadership and organizational learning. International Journal of Business Administration, 9(5), 1-10. doi:https:// doi.org/10.5430/ijba.v9n5p1

Wang, Y., Zheng, Y., \& Zhu, Y. (2018). How transformational leadership influences employee voice behavior: The roles of psychological capital and organizational identification. Social Behavior and Personality: An International Journal, 46(2), 313-321. doi:https://doi.org/10.2224/sbp.6619

Wojtczuk-Turek, A., \& Turek, D. (2015). Innovative behaviour in the workplace: The role of HR flexibility, individual flexibility and psychological capital: The case of Poland. European Journal of Innovation Management, 18(3), 397-419. doi:https://doi.org/10.1108/EJIM-03-2014-0027

Yang, Z., Nguyen, V. T., \& Le, P. B. (2018). Knowledge sharing serves as a mediator between collaborative culture and innovation capability: An empirical research. Journal of Business \& Industrial Marketing, 33(7), 958-969. doi:https://doi.org/10.1108/JBIM-10-2017-0245

Youssef, C. M., \& Luthans, F. (2007). Positive organizational behavior in the workplace: The impact of hope, optimism, and resilience. Journal of Management, 33(5), 774-800. doi:https://doi.org/10.1177/0149206307305562 
Zhang, T., Lu, C., Torres, E., \& Chen, P.-J. (2018). Engaging customers in value co-creation or co-destruction online. Journal of Services Marketing, 32(1), 57-69. doi:https://doi.org/10.1108/IntR-06-2016-0148

Ziyae, B., Mobaraki, M. H., \& Saeediyoun, M. (2015). The effect of psychological capital on innovation in information technology. Journal of Global Entrepreneurship Research, 5(1), 1-12. doi:https://doi.org/10.1186/ s40497-015-0024-9

Zuraik, A., \& Kelly, L. (2019). The role of CEO transformational leadership and innovation climate in exploration and exploitation. European Journal of Innovation Management, 22(1), 84-104. doi:https://doi.org/10.1108/ EJIM-10-2017-0142 